\title{
Os Nervos e a Antropologia Médica Norte-Americana: Uma Revisão Crítica
}

LUIZ FERNANDO DIAS DUARTE*

A autora do prefácio a uma coletânea publicada em 1989. nos EUA. sobre o fenômeno dos nervos diz, a certa altura, que, "de repente, vemos que os nervos são também um fenômeno ocidental". ' A estranheza de tal afirmação, para todos os que sabem quão exclusivamente "ocidental" é o conjunto de representações desenvolvido desde o século XVII em torno da idéia de um "sistema nervoso", e quão fundamentais para a nossa cultura (tanto para a ocidental como um todo, quanto para a brasileira em particular) têm sido as questões dos nervos. sugere que se conheça melhor o contexto de saberes que a suscitou: a Antropologia Médica norte-americana e seus recentes e intensos esforços de produzir conhecimento sobre o fenômeno do nervoso.

Embora a dimensão mais importante deste trabalho seja apresentar uma visão de conjunto da contribuição dessa área acadêmica à questão dos nervos e cotejá-la com outras linhas de informação etnográfica ou de análise socio-

* Professor do Programa de Pós-Graduação em Antropologia Social do Museu Nacional/UFRJ.

1 D. L. Davis e S. M. Low. eds.. Gender. Health and Illness. The Case of Nerves, Nova lorque. Hemisphere Publishing Corporation, 1989. p. IX. 
lógica, sobretudo a que eu próprio avancei, ${ }^{2}$ proponho que ela se associe ao interesse de mostrar como se constrói e desenvolve um objeto de conhecimento em uma subárea muito específica da empresa antropológica contemporânea fortemente marcada pelos saberes de intervenção social com os quais dialoga. Não se trata, ainda assim, de fazer uma etnografia da volumosa e importante Antropologia Médica norte-americana, mas de observá-la a partir do ângulo limitado e viável do que nela, ou em torno dela, se produziu a propósito dos nervos (ou da síndrome dos nervos, como é comumente nomeada a questão nesse campo), discutindo os desafios que se antepõem à plena compreensão antropológica desse fenômeno.

Mais de 30 artigos foram publicados entre 1981 e 1993 em torno do tema dos nervos, seja isoladamente nas revistas especializadas da área $(\mathrm{Cul}$ ture, Medicine \& Psychiatry; Medical Anthropology e Social Science \& Medicine), seja em números temáticos dessas mesmas revistas ou em coletâneas específicas. Seus autores provêm de formações acadêmicas diversas (antropólogos, médicos, psiquiatras, epidemiólogos, assistentes sociais, enfermeiros etc.), trabalhando em departamentos universitários ou em instituições dedicadas à Antropologia ou a temas tais como ecologia, políticas de saúde, estudos sobre mulher, psicoterapia breve para a mulher, tecnologia adequada em saúde etc. Essa produção, que parece se autoconsiderar inaugurada pelo artigo de Setha Low, intitulado "The Meaning of Nervios: A Socio-Cultural Analysis of Symptom Presentation in San Jose, Costa Rica", 3 representa a confluência e transmutação de diversas linhas anteriores (e em parte paralelas) de referência e interpretação do fenômeno dos nervos. ${ }^{4}$

2 L. F. Duarte, "Doença dos Nervos: Um Estudo de Representações e Visão de Mundo de um Grupo de Trabalhadores", in L.M. Rodrigues et alli, eds., Trabalho e Cultura no Brasil, Brasília, Anpocs/CNPq, 1982, pp. 368-76; L. F. Duarte, Da Vida Nervosa. Pessoa e Modernidade entre as Classes Trabalhadoras Urbanas, Tese de Doutorado, PPGAS/Museu Nacional/UFRJ, 1985; L. F. Duarte, Da Vida Nervosa (Nas Classes Trabalhadoras Urbanas). Rio de Janeiro, Jorge Zahar Editor/CNPq, 1986; L. F. Duarte, What it Means to Be Nervous. Competing Concepts of the Person in Brazilian Urban Society, trabalho apresentado no XIII International Congress of the Latin American Studies Association - LASA, Boston, 1986.

3 S. M. Low, "The Meaning of Nervios: A Socio-Cultural Analysis of Symptom Presentation in San Jose, Costa Rica", Culture, Medicine and Psychiatry, vol. 5, n 1, 1981, pp. 25-47.

4 Estarei tratando aqui de uma produção muito diversificada na qualidade e distendida no tempo como se fosse uma única "escola" ou "movimento" dentro da Antropologia Médica norte-americana. A isso me autoriza - possivelmente contra as representações dos "informantes" - o parentesco das questōes que movem os autores resenhados no trato com o referente nervos (ainda que entre eles possa haver dissenso) e as marcas de um campo de trabalho comum: referências bibliográficas cruzadas, recorrência nas revisões temáticas, co-autorias, publicação no mesmo universo de revistas etc. 
Havia certamente uma presença difusa do tema (sobretudo ao tratar de questões de religião e saúde) em obras etnográficas ou folclóricas sobre "cultura popular" no continente norte-americano e no Caribe, que é evocada em Low,${ }^{5}$ por exemplo. Havia ainda uma literatura mais propriamente médico-psiquiátrica (e também norte-americana) que, desde os anos 50, procurava lidar com a "diferença" dos sintomas de perturbação físico-moral nas populações hispânicas dos EUA $^{6}$ - caracterizando-se pelo interesse nos ataques de nervios, sobretudo em Porto Rico (donde a curiosa Puerto Rican Syndrome referida na literatura por algum tempo). ${ }^{7}$ Essa literatura conjugava uma disposição psiquiátrica classificatória típica, com interpretações relacionadas a padrões diferenciais de experiência infantil, aparentemente no âmbito da tradição de estudos da escola de Cultura e Personalidade. ${ }^{8}$ Uma variante dessa linha parece ter se dedicado a populações pobres não-migrantes (nos Apalaches), operando nos moldes do mais estrito reducionismo biomédico ${ }^{9}$ $\mathrm{e}$, eventualmente, lançando mão de interpretações associáveis à teoria da "cultura da pobreza", tão em voga à época nos EUA. ${ }^{10}$

5 S. M. Low, "The Meaning of...", op.cit.

6 Cf., por exemplo, R. D. Mehlman, "The Puerto Rican Syndrome", American Journal of Psychiatry, $\mathrm{n}^{\circ} 118,1961$, pp. 328-32; com uma boa resenha, P. J. Guarnaccia, V. De la Cancella e E. Carrillo, "The Multiple Meanings of Ataques de Nervios in the Latino Community”, Medical Anthropology, vol. 11, n 1, 1989, pp. 47-62.

7 Cf. V. Garrison, "The Puerto Rican Syndrome in Psychiatry and Espiritismo", in V. Crapanzano e V. Garrison, eds., Case Studies in Spirit Possession, Nova Iorque, John Wiley and Sons, 1977.

8 Cf., por exemplo, a crítica a M. Rubio, M. Urdaneta e J. L. Doyle, "Psychopathologic Reaction Patterns in the Antilles Command", U.S. Armed Forces Medical Journal, $\mathrm{n}^{\circ}$ 6, 1955, pp. 1767-72, em P. J. Guarnaccia, V. De la Cancella e E. Carrillo, "The Multiple Meanings...", op. cit., p. 48.

9 "Os enfoques biomédicos nos Apalaches dedicam-se aos sintomas e traduzem esse termo para a nosologia psiquiátrica convencional (C. Wiesel e M. Arny, "Psychiatric Study of Coal Miners in Eastern Kentucky", American Journal of Psychiatry, $\mathrm{n}^{\circ}$ 108, 1952, pp. 617-24; M. Arny, "My Nerves Are Busted", Mountain Life and Work, n' 3, 1955, pp. 24-9; A. M. Ludwig e R. Forrester, "The Condition of 'Nerves'", Journal of the Kentucky Medical Association, $\mathrm{n}^{\circ} 79$, 1981, pp. 333-6; A. M. Ludwig e R. Forrester, "Nerves, but not Mentally", Journal of Clinical Psychiatry, vol. 43, n 5, 1982, pp. 187-90; A. M. Ludwig, "Nerves: A Sociomedical Diagnosis of Sorts", American Journal of Psychotherapy, $\mathrm{n}^{\circ} 36,1982$, pp. 350-7). Há uma preocupação em obter uma definiç̧ão clínica dos nervos, quase sem atenção à experiência quotidiana dos nervos ou aos significados compartilhados pelos usuários do termo." (E. Van Schaik "Paradigms Underlying the Study of Nerves as a Popular Illness Term in Eastern Kentucky", Medical Anthropology, vol. 11, $\mathrm{n}^{\circ} 1,1989$, p. 17).

10 Cf. a crítica a A. M. Ludwig, "Nerves: A Sociomedical...", op. cit., em E. Van Schaik, "Paradigms Underlying...", op.cit., p. 23. 
A constituição desse novo conjunto reflexivo passou pela utilização e teste de diversos conceitos próprios da Antropologia Médica norte-americana, espelhando desenvolvimentos mais amplos do pensamento dessa área no trato com os fenômenos humanos. A preocupação com a contextualização cultural é a tônica, seja do ponto de vista explícito da determinação das relações entre experiência e sentido da doença, seja do ponto de vista latente da definição das unidades culturais significativas. A concepção de cultura prevalecente é a dos "padrões de comportamento". obedecendo a um forte componente funcionalista de atenção à integração e equilíbrio entre "indivíduo" e "sociedade". Essa perspectiva garante uma grande aproximação e continuidade com o pragmatismo das ciências médicas e dos outros saberes de intervenção social a que se associa (apesar das permanentes tentativas críticas de distanciamento do paradigma biomédico). A emergência no interior desse conjunto de correntes voltadas para as dimensões da classe e do gênero e suas concomitantes "dominações" não altera o padrão funcionalista básico, já que apenas enfatiza ou exacerba o pragmatismo a que se encontra aliado (sob a forma de um "intervencionismo crítico" aplicado aos comportamentos).

O uso permanente de categorias como "queixa", "sintoma" ou "síndrome" revela, desde logo, o ponto de partida desses investimentos sobre os nervos: uma questão "médica". freqüentemente suscitada ou pesquisada em contextos médicos. De um modo geral, mesmo quando as etnografias se fazem em condições menos específicas, a discussão se vê fortemente determinada por esse constrangimento originário, impondo a permanência de alguns debates. O exemplo mais marcante é o da recorrência de locuções de mediação entre "cultura" e "sintoma" ou "síndrome". Já no texto original de S. Low ${ }^{11}$ podíamos encontrar o uso de culturally appropriate symptom (sintoma culturalmente adequado) para designar o fenômeno dos nervos. Em um texto posterior, ${ }^{12}$ a mesma autora desencadeava o longo debate sobre a possibilidade ou não de constituírem os nervos uma culture-bound syndrome (síndrome de fronteiras culturais delimitadas) - categoria-chave de toda essa escola de Antropologia Médica. É nesse mesmo sentido que se explicitam as categorias de folk illness,${ }^{13}$ de popular illness term,,${ }^{14}$ de psychosoma-

11 S. M. Low. "The Meaning of...." op.cit.

12 S. M. Low. "Culturally Interpreted Symptoms of Culture-Bound Syndromes: A Cross-Cultural Review of Nerves". Social Science \& Medicine, vol. 21, $\mathrm{n}^{\circ}$ 187. 1985.

13 C. S. Wolf-Dresp, "Nervios as a Culture-Bound Syndrome among Puerto Rican Women". Smith College Studies in Social Work. ${ }^{\circ} 55$, março de 1985, pp. 115-36. 
tic illness, ${ }^{15}$ de illness syndrome,${ }^{16}$ de culturally constituted metaphor for illness ${ }^{17}$ ou de social illness. ${ }^{18}$ Essas categorias estabelecem uma interessante tensão e contraponto com a categoria de distress (aflição, sofrimento, aperto etc.). que, sob diferentes formas, irá expressar a necessidade de reconhecer no nervoso uma experiência social ao mesmo tempo mais ampla e diversificada que a da doença. ${ }^{19}$

14 E. Van Schaik. "Paradigms Underlying...". op. cit.

15 L. Krieger. "Nerves and Psychosomatic Illness: The Case of Um Ramadan”. in D. L. Davis e S. M. Low, eds., Gender, Health and.... op. cit.

16 L. A. Camino, “Nerves, Worriation, and Black Women: A Community Study in the American South“, in D. L. Davis e S. M. Low, eds., Gender, Health and.... op. cit.

17 P. Dunk, "Greek Women and Broken Nerves in Montreal", Medical Anthropology, vol. 11, $\mathrm{n}^{\circ}$ 1. 1989, pp. 29-45.

18 N. Scheper-Hughes. Death without Weeping. The Violence of Every Day Life in Brazil. Berkeley. University of California Press, 1992. A elaboração da distinção metódica entre as três palavras da língua inglesa que designam "doença" (disease, sickness e illness) é uma questão característica da Antropologia Médica norte-americana. Embora nāo pareça haver consenso sobre todas as acepçōes, disease é restringido à expressão de uma realidade patológica biomédica empírica, enquanto se reserva às duas outras expressões a dimensão social. cultural ou "vivencial" desse tipo de fenômeno. Em uma revisão geral da matéria. Young considera que tanto do seu ponto de vista pessoal quanto do de Kleinman, illness estaria reservada a uma espécie de percepção ou vivência individual (individual consciousness) da disease ou da sickness (A. Young, "The Anthropologies of Illness and Sickness". Annual Review of Anthropology, $\mathrm{n}^{\circ} 11$. 1982. pp. 257-85). Ainda segundo Young. seu próprio modelo diferiria do de Kleinman no tocante a sua concepção de sickness: enquanto ele reservaria para esse termo a dimensão sócio-cultural (socially recognizable meanings) desses fenômenos, Kleinman o consideraria como um conceito abrangente de todos os níveis de suas manifestações nessa área. Revelam-se nessa polêmica algumas das maiores marcas do campo: a oposição entre "biomédico/orgânico " e "não-biomédico/orgânico", entre "individual" e "não-individual", e entre "social " e "cultural".

19 Ver, por exemplo, psychosocial distress (S. M. Low. "The Meaning of....". op. cit.): folk idiom of stress and distress (N. Scheper-Hughes. "The Madness of Hunger: Sickness, Delirium, and Human Needs". Culture. Medicine and Psychiatry, vol. 12, n 4. 1988 e N. Scheper-Hughes. Death without Weeping..., op. cit.): metaphor for social distress (M. H. Clark. "Nevra in a Greek Village: Idiom. Methaphor. Symptom, or Disorder?”, in D. L. Davis e S. M. Low, eds.. Gender. Health and.... op. cit.); idiom of distress (P. J. Guarnaccia e P. Farias, .The Social Meaning of Nervios: A Case Study of a Central American Woman", Social Science \& Medicine. vol. 26. $\mathrm{n}^{\circ} 12,1988$; L. A. Camino, "Nerves, Worriation...". op. cit.); distress syndrome (S. M. Low. "Health, Culture and the Nature of Nerves: A Critique", Medical Anthropology. vol. 11. $\mathrm{n}^{\circ}$ 1. 1989. pp. 91-5): emotional and social distress (D. L. Davis e P.J. Guarnaccia. "Health. Culture and the Nature of Nerves: Introduction". Medical Anthropology, vol. 11. $\mathrm{n}^{\circ}$ 1, 1989, pp. 1-13); normal expression of social distress (P. Dunk, "Greek Women and...", op. cit.); embodied distress (K. Finkler. "The Universality of Nerves", in D. L. Davis e S. M. Low. eds.. Gender, Health and..., op. cit.): expression of distressful physical and emotional states (D. L. Davis e R. Whitten, "Medical and Popular Traditions of Nerves". Social Science \& Medicine, vol. 26, $\mathrm{n}^{\circ}$ 12, 1988, pp. 1209-22). 
A locução culture-bound syndrome resume, desde o início, a discussão sobre as fronteiras culturais do fenômeno dos nervos. Em um artigo de revisão da literatura, ${ }^{20}$ são arroladas como alternativas nesse nível que ele constitua uma "síndrome de fronteiras culturais delimitadas", uma "síndrome culturalmente interpretada" ou um fenômeno "universal". ${ }^{21}$ As dificuldades com o conceito de "cultura" utilizado revelam-se também nas ambigüidades que irão presidir a definição da história do fenômeno: os autores hesitam ante a diversidade das formas culturais dentro da cultura ocidental moderna (conceito que, aliás, só aparece muito ocasionalmente). De uma maneira geral, é como se a cultura norte-americana (ou melhor, a cultura "dominante", "abrangente", "erudita" ou "oficial" norte-americana) se confundisse com a "cultura ocidental" (como na referência citada do prefácio a Davis \& Low), ${ }^{22}$ de tal modo que manifestações culturais aparentemente associáveis a populações latino-americanas ou de origem latina (ou negras, ou ligadas a quaisquer minorias étnicas) parecessem de algum modo "indígenas" ou "bárbaras". De uma maneira geral, todas essas "minorias étnicas" são consideradas como ainda portadoras de suas "culturas de origem", de tal modo que se chega a postular o estudo das situações metropolitanas como chave para a compreensão do comportamento dos "migrantes". Os estudos que recorrem ao conceito de "cultura popular" ou folk (ou à dicotomia entre "grande" e "pequena tradição"), ${ }^{23}$ não o fazem interagir, porém, de modo sistemático, com as noções imprecisas das culturas nacionais ou dos grandes subsistemas dentro da cultura ocidental (tais como os de "cultura latina" ou "negra"). Um outro vetor de referência utilizado - que poderia ser discutido no contexto da oposição entre grande e pequena tradição - é o da distinção entre "cultura profissional" e "cultura leiga", ${ }^{24}$ que é expressivo, mais uma vez, do enfoque dado a partir dos saberes médicos.

20 D. L. Davis e P.J. Guarnaccia, "Health, Culture and...", op. cit., p. 7.

21 O que permite que um dos autores diga, muito lucidamente, que: "Se ela tem fronteiras culturais delimitadas, essas fronteiras não podem ser outras senão as do mundo ocidental ou da tradição médica galênica" (S. M. Low, "Culturally Interpreted Symptoms...", op. cit.).

22 D. L. Davis e S. M. Low, eds., Gender, Health and..., op. cit. Em um dos trabalhos, realizado em uma aldeia do Peru, as Latin American cultures são opostas à Western society, o que permite que a autora diga que "diferentemente dos EUA e do Canadá, onde os distúrbios emocionais são vistos como separados e distintos dos distúrbios físicos, no Peru toda doença [illness] é vista como orgânica" (E. A. Barnett, "Notes on Nervios: A Disorder of Menopause", in D. L. Davis e S. M. Low, eds., Gender, Health and..., op. cit., p. 164).

23 Cf. D. L. Davis e R. Whitten, "Medical and Popular...", op. cit.

24 Cf., por exemplo, D. L. Davis, "George Beard and Lydia Pinkham: Gender, Class, and Nerves 
Dificuldade idêntica apresenta-se no trato com a história dos nervos. Há, em primeiro lugar, autores que parecem genuinamente surpresos com a existência de sistemas exóticos de saber sobre a Pessoa baseados nos nervos, como se nada tivessem a ver com a cultura norte-americana ou ocidental. Já os autores conscientes da importância da dimensão histórica da questão expressam uma visão linear e anacrônica da "evolução" do fenômeno a partir dos gregos. ${ }^{25} \mathrm{~A}$ continuidade lexical e a discutível continuidade de referente empírico entre os nervos de Hipócrates e os contemporâneos justificam uma leitura que se poderia justamente chamar de "continuísta", empanando a percepção das rupturas radicais de sentido que caracterizam a história das relações entre corpo e mente dentro da tradição ocidental. Algumas análises expressam uma maior consciência da dimensão das transformações históricas do fenômeno, sem chegar no entanto a alterar fundamentalmente a perspectiva continuísta. ${ }^{26}$ É interessante observar que, para alguns autores, a evocação da figura da neurastenia na história recente dos Estados Unidos, ou da cultura anglo-saxã, representou uma importante estratégia contextualizadora. ${ }^{27}$ Um esclarecedor artigo de Dona Davis ${ }^{28}$ sobre a neurastenia norte-americana é o apogeu dessa compreensão mais historicizada e contextualizada dentro do movimento. De um modo geral, porém, permanece uma visão um tanto restrita ou paroquial da questão, esquecendo-se a amplitude que assumiu a configuração da neurastenia (ainda que essa figura médica tivesse sido cunhada nos EUA) em toda a área de influência da

in Late 19th. Century America". in D. L. Davis e S. M. Low, eds., Gender, Health and..., op. cit., p. 94.

25 Cf. N. Scheper-Hughes, "The Madness of Hunger...", op. cit., p. 432; M. Lock. "Words of Fear, Words of Power: Nerves and the Awakening of Political Consciousness", Medical Anthropology, vol. $11, \mathrm{n}^{\circ} 1,1989, \mathrm{p} .84$. Repete-se aqui a distorção das histórias profissionais em geral (como é notoriamente o caso das histórias da medicina ou da psiquiatria), que repetem a falácia da evoluçâo linear da razão, fazendo com que todos os episódios sejam lidos como espécies de prefiguraçōes imperfeitas do saber contemporâneo. As poucas análises européias do fenômeno dos nervos padecem da mesma limitação: o importante trabalho de Jodelet faz uma menção apenas sumária e superficial à sua "Ionga história"(D. Jodelet, Folies et Représentations Sociales, Paris, PUF. 1989, p. 379).

26 Cf. S. M. Low, “Culturally Interpreted Symptoms...”, op. cit., p. 189; S. Cayleff, "Prisoners of their Own Feebleness: Women, Nerves and Western Medicine - A Historical Overview", Social Science \& Medicine, vol. 26, $\mathrm{n}^{\circ}$ 12, 1988, p. 1201; D. L. Davis e R. Whitten, "Medical and Popular...”, op. cit., p. 1209.

27 S. M. Low, “Culturally Interpreted Symptoms...", op. cit., p. 189; D. L. Davis e P. J. Guarnaccia, "Health. Culture and...", op. cit., p. 9; D. L. Davis e R. Whitten, "Medical and Popular...", op. cit.

28 D. L. Davis, "George Beard and...," op. cit. 
cultura ocidental moderna - com implicações fundamentais para a difusão dos saberes dos nervos. ${ }^{29}$

O que se destaca deste esboço inicial é sobretudo a força da influência do empirismo médico, que impõe uma necessária superposição ou confusão entre o objeto da anatomia animal (e humana) que se supõe constituírem os "nervos" ou o "sistema nervoso" e o conjunto de perturbações, afecções, sofrimentos, queixas ou sintomas que vieram na cultura ocidental a ser associados de forma sistemática àqueles entes (ou à sua representação). Essa associação cultural ou simbólica - manifestação específica do problema universal da sistematização das perturbações físico-morais - foi reificada pelos saberes médicos a partir do século XVII na figura das "doenças nervosas", culminando com o grande florescimento oitocentista das classificações psiquiátricas instruídas pela postura "fisicalista". ${ }^{30}$ A neurastenia, assim como o complexo da degenerescência, foram apenas capítulos da história dessa reificação das perturbações físico-morais sob a forma de "doenças". A Antropologia Médica norte-americana aceita os termos em que a ideologia médica ocidental coloca a questão ao procurar relativizar essa representação apenas pela demonstração do caráter social ou culturalmente determinado de suas manifestações, e não do caráter originariamente arbitrário de sua existência mesma ${ }^{31}$ A hipótese de uma correlação "real" entre o sistema nervoso, o acervo vastíssimo das expressões físico-morais da "perturbação" hu-

29 Ver, por exemplo, os trabalhos de Kleinman sobre a utilização da classificação de neurastenia na China contemporânea (A. Kleinman, Social Origins of Distress and Disease: Depression, Neurasthenia and Pain in Modern China, New Haven, Yale University Press, 1986 e A. Kleinman, "Neurasthenia and Depression: A Study of Somatization and Culture in China". Culture, Medicine and Psychiatry, $\left.\mathrm{n}^{\circ} 6,1982, \mathrm{pp} .117-90\right)$.

30 Cf. L. F. Duarte, Da Vida Nervosa (Nas Classes..., op. cit., cap. IIIb.

31 Apesar de observações isoladas como a de Dona Davis de que: "apresentar o nervoso como uma doença [illness or sickness] não faz justiça à maneira como esse termo é empregado em Grey Rock Harbour" (D. L. Davis, "The Variable Character of Nerves in a Newfoundland Fishing Village”, Medical Anthropology, vol. 11, n 1, 1989. p. 76), ou a de Van Schaik de que “As relações de desigualdade e dominação embutidas na queixa do nervoso, tal como se expressa no contexto dos Apalaches, apontam para uma interpretação do nervoso como expressão de relações sociais, mais do que como doença [illness]" (E. Van Schaik, "Paradigms Underlying..., op. cit., p. 26). É possível que essa contradição seja representativa de um problema maior da Antropologia Médica: o de constituir um "enfoque centrado na significação dos fenômenos médicos" (A. Kleinman, "The Meaning Context of Illness and Care: Reflections on a Central Theme in the Anthropology of Medicine", Sciences and Cultures. Sociology of the Sciences, V, 1981, p. 161); ou seja, que se dispõe a operar com a construção simbólica dos fatos humanos mas, ao mesmo tempo, aceita que alguns deles sejam predefinidos como "médicos" (que é, fora de dúvida, uma "construção" cultural específica). 
mana (minha proposta, talvez, para o que essa literatura chama de distress ) e uma doença ou conjunto de doenças permite que se chegue a operar com a hipótese da "universalidade" do fenômeno, ainda que seja para negá-la ou infirmá-la paulatinamente. Nesse sentido, poder-se-ia dizer que a medicalização dos nervos.não é real em si, mas apenas enquanto representação que se expõe à análise antropológica.

É ainda notável que, no esforço de fugir às formas mais antiquadas e lineares do empirismo médico, essa literatura aceite o que se poderia chamar de um "empirismo psiquiátrico" ou "psicológico", em que categorias tais como ansiedade, angústia, stress, pânico ou depressão — outras tantas formas culturais de nomear ou definir as perturbações, tal como o nervoso - são usadas como entes reais, seja como doenças em si mesmas, seja como causas ou sintomas "emocionais" de situações de doença.

à reificação da "doença nervosa" corresponde, assim, uma reificação da versão psicologizada do homem moderno. Perpassam esses trabalhos não só a concepção difusa e mais grosseira de que os sujeitos civilizados são os que operam com noções claras, distintas, racionais, do que é corpo e do que é espírito ou mente (por oposição aos saberes dos nervos, que confundiriam esses planos classificatórios), ${ }^{32}$ mas também a idéia de que as categorias psicologizantes contemporâneas expressam a realidade do que se passa com os seres humanos, enquanto sistemas como o do nervoso são - apenas eles — "culturais" ou "simbólicos".

Algumas poucas figuras nosológicas prevalecem nesse contexto - e com elas pretende-se explicar a realidade "psicopatológica" do nervoso. Porém, há uma complexa relação com o quadro classificatório psiquiátrico: alguns autores acompanham linearmente as classificações biomédicas, enquanto outros recusam certas categorias em nome da crítica à redução biomédica e passam a adotar outras, consideradas possivelmente mais abstratas ou menos comprometidas. As figuras são as da somatização $;^{33}$ conversão

32 É sintomático dessa visão o peso da argumentação meio lévy-bruhliana de que esses saberes não fazem distinção entre os dois planos (e nāo, como proponho, que eles são uma teoria das relações entre os dois planos). A evocação da "histeria" como forma bárbara dessa indistinção transparece na citação de um dos autores de que a categoria psiquiátrica de IHSS (Idiopathic Hypertrophic Subaortic Stenosis) - cunhada no contexto da tal "síndrome porto-riquenha" - era jocosamente lida como Idiopathic Hysteries of the Spanish Sort - literalmente Histerias Idiopáticas do Tipo Espanhol (apud P. J. Guarnaccia, V. De la Cancella e E. Carrillo, "The Multiple Meanings...", op. cit., p. 49).

33 Cf. C. S. Wolf-Dresp, "Nervios as a Culture-Bound...", op. cit., p. 120; M. Nations, L. A. Camino e F. Walker, "Nerves: Folk Idiom for Anxiety and Depression", Social Science \& 
(por onde transparece a velha histeria) $;^{34}$ depressão $0,{ }^{35}$ ansiedade, ${ }^{36}$ stress, ${ }^{37}$ pânico ${ }^{38}$ e esquizofrenia. ${ }^{39}$ Em muitos casos são feitas remissões às tabelas de classificações psiquiátricas oficiais, e nem sequer a consciência do fato de que uma categoria tão importante quanto a da neurastenia pode acabar desaparecendo do catálogo $0^{40}$ suscita uma disposição de relativização mais radicalmente antropológica. Parece, antes mesmo, confirmar a visão linear do progresso da razão e da ciência ocidentais no esclarecimento da experiência humana. Um dos artigos sobre o tema enuncia claramente no título: "Nervos: Categoria Folk para Ansiedade e Depressão". ${ }^{41}$ Diversos autores manifestam sua disposição piedosa em ver corrigidas ou adequadas as clas-

Medicine, vol. 26, $\mathrm{n}^{\circ}$ 12, 1988, p. 1254; S. M. Low, "Health, Culture and...", op. cit., p. 94; S. M. Low, "Gender, Emotion, and Nervios in Urban Guatemala", in D. L. Davis e S. M. Low, eds., Gender, Health and..., op. cit., p. 137; P. Dunk, "Greek Women and...". op. cit., pp. 41-2. •

34 Cf. S. M. Low, "The Meaning of...", op. cit., p. 36; P. J. Guarnaccia, V. De la Cancella e E. Carrillo. "The Multiple Meanings...", op. cit., p. 48.

35 S. M. Low, "The Meaning of...", op. cit., p. 36; M. Nations, L. A. Camino e F. Walker, “Nerves: Folk Idiom...", op. cit., p. 1253; P. Dunk, "Greek Women and...", op. cit., p. 37; J. A. Sluka, "Living on their Nerves: Nervous Debility in Northern Ireland", in D. L. Davis e S. M. Low, eds., Gender, Health and..., op. cit., p. 220; R. Finerman, "The Burden of Responsibility: Duty, Depression, and Nervios in Andean Ecuador", in D. L.Davis e S. M. Low, eds., Gender, Health and..., op. cit., p. 145; M. Kay e C. Portillo, "Nervios and Dysphoria in Mexican American Widows", in D. L. Davis e S. M. Low, eds., Gender, Health and..., op. cit., p. 280.

36 S. M. Low, "The Meaning of...", op. cit., p. 36: M. Nations, L. A. Camino e F. Walker, "Nerves: Folk Idiom...", op. cit., p. 1256; P. Dunk, "Greek Women and...", op. cit., p. 37; K. Finkler, "The Universality of...". op. cit., p. 178; D. L. Davis e P. J. Guarnaccia, "Health. Culture and...", op. cit., p. 8; J. D. Koss-Chioino, "Experience of Nervousness and Anxiety Disorders in Puerto Rican Women: Psychiatric and Ethnopsychological Perspectives", in D. L. Davis e S. M. Low, eds., Gender, Health and..., op. cit., pp. 245 e 253; M. H. Clark, "Nevra in a Greek...", op. cit., p. 215; E. A. Barnett, "Notes on Nervios...", op. cit., pp. 168-9.

37 R. Finerman, "The Burden of...", op. cit., p. 154; K. Finkler, "The Universality of..., op. cit., p. 173; J. D. Koss-Chioino, "Experience of Nervousness...”, op. cit., p. 253.

38 Cf. M. Nations, L. A. Camino e F. Walker, "Nerves: Folk Idiom...", op. cit., p. 1254; J. D. Koss-Chioino, "Experience of Nervousness...", op. cit., p. 252; D. L. Davis e P. J. Guarnaccia, "Health, Culture and...", op. cit., p. 8.

39 J. Jenkins, "Conceptions of Schizophrenia as a Problem of Nerves: A Cross-Cultural Comparison of Mexican-Americans and Anglo-Americans", Social Science \& Medicine, vol. 26, $\mathrm{n}^{\circ}$ 12,1988 , em geral.

40 Cf. S. Reynolds e L. Swartz, "Professional Constructions of a 'Lay' Illness: 'Nerves' in a Rural 'Coloured' Community in South Africa", Social Science \& Medicine, vol. 36, n 5, 1993, p. 658 .

41 M. Nations, L. A. Camino e F. Walker, “Nerves: Folk Idiem...”, op. cit. 
sificações psiquiátricas, ${ }^{42}$ reforçando ainda mais a substantivação básica que as envolve. ${ }^{43}$ Parte dessa disposição reformadora se volta para a definição de cada uma das figuras, supondo evitar confusões e superposições ou provar associações consideradas inexistentes. Outra parte se volta para uma maior "abertura" às variações interculturais, propondo uma ampliação ou flexibilização das listas nosológicas - incluindo categorias folk ou "culturalmente interpretadas", como a dos nervos.

Há, porém, importantes exceções à reificação dessas outras categorias de perturbação, como Scheper-Hughes, que reconhece o stress como um "conceito folk" 44 (no que é seguida por Reynolds \& Swartz ${ }^{45}$ ) e enfatiza a dimensão etnocêntrica do uso da categoria "somatização" como mecanismo de defesa "primitivo", 46 Margaret Lock, que critica o emprego pela "profissão médica" da categoria "somatização" para designar experiências como as dos nervos e ataques de nervos ${ }^{47}$ e Davis \& Guarnaccia, que sugerem que "o nervoso não pode ser claramente coberto por uma categoria diagnóstica da DSM-III, já que atravessa diversas categorias. Isso acontece porque o nervoso não é apenas uma rubrica popular para os diagnósticos psiquiátricos, mas, antes, uma categoria culturalmente construída e culturalmente significativa que pode existir em relação às categorias diagnósticas psiquiátricas, mas não se resumir a elas". ${ }^{48}$

Alguns trabalhos apresentam material de pesquisa riquíssimo sobre as outras representações (psicologizadas) das perturbações físico-morais entre informantes de diversos tipos, ao tentar delimitar as fronteiras do recurso às representações dos nervos. A densidade desse material é, no entanto, sistematicamente reduzida pela sua não-relativização. Considero paradigmático o caso de uma informante de Dona Davis, que pede para apresentar um novo depoimento sobre os nervos e reformula seu modelo de modo a compatibili-

42 Cf., por exemplo. M. Oquendo, E. Horwath e A. Martinez, "Ataques de Nervios: Proposed Diagnostic Criteria for a Culture Specific Syndrome". Culture, Medicine and Psychiatry, $\mathrm{n}^{\circ}$ 16. 1992, pp. 367-76.

43 Um significativo sintoma desse estado atual do senso comum erudito a respeito das perturbaçōes físico-morais é o de que a própria ficha catalográfica da importante coletânea publicada sob o título de Gender. Health, and Illness. The Case of Nerves não inclui a referência nerves, mas sim anxiety e depression.

44 N. Scheper-Hughes, Death without Weeping..., op. cit., p. 175.

45 S. Reynolds e L. Swartz, "Professional Constructions of...". op. cit., p. 658.

46 N. Scheper-Hughes, Death without Weeping..., op. cit., p. 185.

47 M. Lock, "Words of Fear...", op. cit., p. 85.

48 D. L. Davis e P.J. Guarnaccia, "Health, Culture and...", op. cit., p. 8. 
zar as informações que antes fornecera sobre o assunto com uma versão mais "psicologizada", que ela considerava explicitamente mais "moderna" (e, inclusive, possivelmente mais legítima para exposição a um pesquisador universitário). Seu fascinante resumo de que "now nerves is depression, not really nerves" (os nervos são mais é depressão, não nervos de verdade) ${ }^{49}$ merece grande atenção em termos de uma compreensão antropológica das diferentes formas da Pessoa e das perturbações nas sociedades ocidentais modernas (e do sentido dos seus deslocamentos)..$^{50}$ É ainda ilustrativo o exemplo da excelente análise de Janis Jenkins, comparando representações cruzadas sobre a esquizofrenia e o nervoso entre famílias Anglo-American e Mexican-American. Ressalta o mesmo deslizamento da visão de mundo dos Anglo-Americans das representações nervosas para as "psicologizadas", que a mãe de um paciente assim expressa: "durante um tempo eu usei a palavra 'crise nervosa', até me dar conta que se tratava de doença mental". ${ }^{51}$ A autora percebe algumas das maiores implicações dos resultados de seu estudo e registra "uma mudança histórica e integração dinâmica dos conceitos anglo-americanos de distúrbio mental" que aí se revelam..$^{52}$ Considerá seus resultados como "uma crítica das conclusões universalistas relativas à generalidade transcultural das concepções folk da psicose", ${ }^{53}$ mas não chega a se dar conta que seria necessário compreender também como funcionam as representações eruditas da psicose ou da esquizofrenia (e não apenas as representações populares sobre elas). ${ }^{54}$

49 D. L. Davis, "The Variable Character of...", op. cit., p. 72.

$50 \mathrm{Se}$, como proponho, os nervos constituem um sistema integrado de representação da pessoa e de suas perturbações, que se opõe ao modelo psicologizado moderno, esses relatos de confronto ou hesitação entre códigos são altamente reveladores e deveriam merecer uma maior atenção. Há uma história exemplar em G. Lagadec, "Discours des Malades. Esquisse d'une Théorie des Conceptions Populaires de la Physiopathologie", Bulletin d'Ethnomédecine, n⿳3 $33,1^{\circ}$ trim. de 1985 , que nos mostra um médico, acostumado a lidar com as "queixas nervosas" de sua clientela popular, ver rechaçada e ridicularizada uma interpretação vazada nesse código apresentada a uma cliente professora e "psicanalizada" (como pôde, a posteriori, verificar) (idem, p. 17).

51 J. Jenkins, "Conceptions of Schizophrenia...", op. cit., p. 1237.

52 Idem, p. 1240.

53 Idem, p. 1242.

$54 \mathrm{O}$ mesmo fenômeno de afastamento da linguagem dos nervos da parte dos segmentos mais estabelecidos da sociedade norte-americana ou mais próximos de sua cultura dominante altamente individualizada é demonstrado em M. Kay e C. Portillo, "Nervios and Dysphoria...", op. cit., ao dizer, a propósito das viúvas Mexican-American que estuda, que "quanto mais aculturadas, menos são afligidas por uma sintomatologia ligada aos nervos" (idem, p. 287); ou ainda em P. J. Guarnaccia et alli, "Si Dios Quiere: Hispanic Families Experiences of Caring for a Seriously Mentally Ill Family Member”, Culture, Medicine and Psychiatry, nº 16, 1992, pp. 
Essa reificação erudita dos nervos em uma "síndrome" ou "doença dos nervos" impõe uma relação de opacidade com o léxico interlingüístico a ela relacionado. Os autores que trabalharam em contextos hispânicos hesitam ante a possibilidade de utilizar indistintamente nerves ou nervios. Já o nevrika/nevra encontrado nas populações de fala grega e o nerfiza descrito para o Egito são incorporados sem maiores inquietações. à exceção do texto inaugural de Setha Low $^{55}$ e do trabalho de Clark sobre o nevra na Grécia ${ }^{56}$ não se considera necessário compreender a extensão semântica desses termos no contexto das línguas em que emergem ou de suas variações locais. ${ }^{57} \mathrm{Os}$ ataques de nervos aparecem na literatura mais consistentemente como culture-bound, já que os autores não parecem considerar razoável utilizar alternativamente nervous crisis ou nervous breakdown. O desinteresse pela dimensão mais intrinsecamente lingüística do fenômeno confirma a disposição em considerá-lo como um dado anatômico e patológico, independente de suas expressões lexicais. ${ }^{58}$ As dificuldades de transitar entre as locuções equivalentes dentro das línguas ocidentais expressam, antes, a insegurança ou imprecisão com as fronteiras culturais que uma preocupação com a sua efetiva estruturação semântica.

É significativa também a maneira pela qual a literatura negligencia a íntima relação que os saberes populares dos nervos mantêm com a religião.

187-215, ao comparar Hispanic-Americans e European-Americans: "As famílias de origem européia encaravam mais freqüentemente o problema como médico e tinham sido mais influenciadas pelo modelo médico da esquizofrenia" (idem, p. 194).

55 S. M. Low, "The Meaning of...", op. cit.

56 M. H. Clark, "Nevra in a Greek...", op. cit.

57 É pena que não se disponha de uma análise semântica da categoria nerfiza, no contexto da língua árabe (cf. L. Krieger, "Nerves and Psychosomatic...", op. cit.). Ela nos permitiria dispor de um quadro comparativo com os deslizamentos desse vocábulo no interior das línguas européias. Uma análise também muito superficial e formal do uso do termo em língua francesa pode ser encontrada em G. Lagadec, "Discours des Malades...", op. cit., p. 11.

58. Ver, como exemplo dessa universalização pela reificação: "A condição referida como nervoso consiste em uma experiência corporal totalizante que se caracteriza por uma generalizada preocupação, ansiedade e tremores experimentados em todo o corpo, porque encarna generalizados acontecimentos negativos. Ela é assim uma condição humana universal que se pode encontrar em todas as culturas e que pode ser chamada de nervoso ou de outra expressão análoga" (K. Finkler, "The Universality of...", op. cit., p. 178, grifo meu). Pode-se - em contraposição e como exemplo da dimensão simbólica, de linguagem, do nervoso - evocar o fascinante caso descrito em Lagadec, de uma paciente que relatava entre os sintomas ligados ao seu nervoso a existência de uma hérnia, cujo nome ela pronunciava em francês de tal modo que soava mais ou menos como "um nervo-nem" (un hernie: an-nér-ni) (cf. G. Lagadec, "Discours des Malades...", op. cit., p. 20). 
Embora as referências a situações de proximidade com essa área sejam múltiplas - ora mais superficiais, ora mais detalhadas - as experiências religiosas aparecem realmente como uma outra dimensão, um outro patamar de realidade. A reificação medicalizante distancia os nervos de sua continuidade com as outras formas de expressão ou resposta às perturbações físicomorais, em que se inclui uma miríade de experiências "religiosas" como o transe, a possessão, as promessas, as invocações etc. ${ }^{59}$

O trajeto dessa produção pode ser, em geral, compreendido como uma progressiva e explícita tentativa de afastamento e crítica da redução medicalizante do nervoso e uma busca concomitante de novas bases de racionalidade para a sua compreensão. Além de se sustentarem quase sempre implicitamente na citada redução psicologizante, esses esforços vieram a substituir explicitamente a redução medicalizante por um tripé formado pelas questões do poder/classe/dominação, da oposição de gêneros e da migração/mudança.

É provavelmente Scheper-Hughes quem primeiro expressa com toda a clareza essa transição da redução "biomédica" para a redução "política". Em um artigo de 1988 ela critica o reducionismo biomédico em nome do estabelecimento de uma Antropologia Médica "crítica", ou seja, baseada em uma perspectiva "marxista" de interpretação dos fenômenos sociais pelas dimensões do poder e da dominação. ${ }^{60}$ Essa disposição teórica — que será defendida mais amplamente em outro trabalho da autora ${ }^{61}$ — não impedirá que a mesma ainda se refira ao nervoso como folk ailment ou como folk illness syndrome. Outros autores seguirão nesse empreendimento, ainda que

59 Há referências a relaçōes do nervoso com feitiçaria entre Mexican-Americans em J. Jenkins. "Conceptions of Schizophrenia...", op. cit.: com o "espiritismo" no contexto porto-riquenho em P. J. Guarnaccia, M. Rubio-Stipec e G. Camino, "Ataques de Nervios in the Puerto Rico Diagnostic Interview Schedule: The Impact of Cultural Categories on Psychiatric Epidemiology". Culture, Medicine e Psychiatry. ${ }^{\circ}$ 13. 1989. pp. 275-95: com curandeiros "espiritual istas" no México em K. Finkler, "The Universality of...". op. cit.; com a oposição entre possessão islâmica tradicional e fundamentalismo contemporâneo no Egito em L. Krieger. "Nerves and Psychosomatic...",op. cit.; com cultos locais de possessão na Grécia em M. H. Clark, "Nevra in a Greek...", op. cit.: com sistemas populares de cura porto-riquenhos em J. D. Koss-Chioino, "Experience of Nervousness...", op. cit.: com "fatores espirituais e religiosos" em P. J. Guarnaccia et alli. "Si Dios Quiere...", op. cit.; com a religiosidade de porto-riquenhos em Nova Iorque em M. Swerdlow, "'Chronicity'. 'Nervios', and Community Care: A Case Study of Puerto Rican Psychiatric Patients in New York City “. Culture, Medicine and Psychiatry, $\mathrm{n}^{\circ}$ 16, 1992. pp. 217-35: com "crenças espirituais" no Caribe hispânico em M. Oquendo. E. Horwath e A. Martinez. “Ataques de Nervios...". op. cit.; e com o culto do xangô do Nordeste brasileiro em N. Scheper-Hughes, Death without Weeping.... op. cit.

60 N. Scheper-Hughes, "The Madness of Hunger..... op. cit., pp. 429 e 433.

61 N. Scheper-Hughes, Death without Weeping..., op. cit. 
mais baseados nas evidências etnográficas da amplitude simbólica do fenômeno do que em um postulado teórico mais geral. ${ }^{62}$

O reducionismo "político" parte da constatação de que os "pacientes" do nervoso são quase exclusivamente membros das classes dominadas ou subordinadas em todas as sociedades nacionais em que foram detectados, para propor que o fenômeno seja encarado como expressão direta dessa condição social. Por força da reificação prevalecente, misturam-se assim, nessa perspectiva, a dimensão vital das perturbações - certamente inseparável das condições de vida - e a dimensão simbólica da linguagem cultural em que se expressam essas experiências vividas.

Três posições podem ser aí distinguidas. A primeira é a que inclui a dimensão "política" como uma dentre as causalidades atribuíveis ao desencadeamento e desenvolvimento do nervoso. ${ }^{63} \mathrm{~A}$ segunda, é a que opera com um modelo de base "marxista" que lhe permite articular uma crítica mais consistente ao biodeterminismo; e a terceira é a que, baseada em uma posição "pós-moderna". aspira a ultrapassar a própria disposição "crítica".

Scheper-Hughes e Van Schaik encarnam a segunda posição, na qual prevalece explicitamente a representação da ideologia como encobridora e alienante: "Expressando por meio da queixa dos nervos a desigualdade e a dominação por eles experimentada, esses indivíduos participam da medicalização e mistificação de suas próprias experiências vividas". ${ }^{64} \mathrm{Ou}$ ainda, no dizer de Scheper-Hughes: "A categoria dos nervos fornece a uma população agitada, nervosa e faminta, no mínimo uma forma menos perigosa de lidar com a dor e de registrar o seu descontentamento e desconfiança. Mediante a categoria dos nervos, o terror e a violência da fome são socializados e domesticados e têm suas origens escondidas". ${ }^{65}$ Ainda uma vez, os desenvolvimentos dessas análises do nervoso parecem fazer ecoar questões antigas

62 É o caso de P. J. Guarnaccia, V. De la Cancella e E. Carrillo, "The Multiple Meanings...". op. cit. . que vai opor o "modelo médico-psiquiátrico" e o "modelo popular" (idem. p. 59): de D. L. Davis e P.J. Guarnaccia. "Health. Culture and...", op. cit., que adverte contra o perigo de "medicalizar o que é essencialmente um problema social" (idem, p. 7. grifo meu): e de S. M. Low. "Gender. Emotion, and...”. op. cit.. que vai se referir criticamente a uma "medicalização do distress" (idem. p. 132).

63 Ver. por exemplo. a proposta de uma "teoria coerente dos nervos baseada na questão estrutural da desigualdade pessoal, social e cultural" (S. M. Low. "Health, Culture and...". op. cit.. p 92); ou a referência geral de Sluka a "relaçōes de desigualdade e dominação" (J. A. Sluka. "Living on their...". op. cit. p. 240).

64 E. Van Schaik. "Paradigms Underlying...." op. cit.. p. 25.

65 N. Scheper-Hughes, Death without Weeping..., op. cit., p. 214. 
e básicas da Antropologia Médica, como a oposição entre uma perspectiva centrada na "significação" (meaning) e outra na "organização social", associadas sucessivamente por Young a uma anthropology of illness e a uma anthropology of sickness. ${ }^{66} \mathrm{~A}$ defesa que Van Schaik faz do "paradigma crítico" contra o "hermenêutico" evoca a preeminência das "relações sociais" subjacentes à "dominação" sobre os "significados" barganhados na "comunicação" social. ${ }^{67}$

Lock expressa, finalmente, a última posição, ao ver nos nervos a manifestação de uma "consciência política" que colocaria em xeque as teorias ligadas à "cosmologia ocidental pós-iluminista" ou à "cultura pós-industrial". Essa interpretação se prende ao tema da suposta integração (ou nãoseparação) entre corpo e espírito nos discursos dos nervos, de que me ocuparei mais adiante. A expectativa da "possibilidade de uma dialética criativa e equilibrada entre a mente e o corpo" 68 faz atribuir ao saber popular dos nervos a condição iluminadora de "expressão metafórica da experiência da opressão, aparentemente usada de um modo bastante consciente". ${ }^{69} \mathrm{De}$ modo paralelo à interpretação de Scheper-Hughes, a linguagem popular dos nervos é aqui considerada como "potencialmente política e mesmo revolucionária",70 por oposição à opacificação produzida pela sua redução medicalizante. ${ }^{71}$

66 A. Young, "The Anthropologies of...", op. cit.

67 A autora contrasta o "paradigma crítico", sucessivamente, com o "biomédico" e o "hermenêutico". fazendo apenas uma rápida menção à interpretação da "cultura da pobreza" (que não se enquadra naquelas rubricas). As questōes do sentido, da significação, da linguagem ficam limitadas à perspectiva hermenêutica (que as reduz aos níveis da textualidade e da comunicação). As perspectivas plenamente "simbólicas" ou "culturais" (nas profícuas linhagens de Boas e Mauss) ficam ausentes do seu quadro, possivelmente por não ter uma repercussão significativa no subcampo da Antropologia Médica - a "Antropologia da doença" francesa, por exemplo. fica significativamente fora do seu desenho. Seria interessante contrapor essa posiçâo à crítica de L. Dumont (justamente um "maussiano") às "Antropologias particulares" ou "anti-Antropologias" (L. Dumont, "La Communauté Anthropologique et l'Idéologie", L'Homme, vol. XVIII, no 3-4, 1978, pp. 83-110).

68 M. Lock, "Words of Fear...", op. cit., p. 80.

69 Idem, pp. 85-6.

70 Idem, p. 86.

71 Lock equaciona o nervoso com o "mágico" ou "primitivo" para conceder-lhe, em seguida, seus privilégios "antimodernos": "Prender-se a termos como nevra pode ser equacionado a acreditar no mau-olhado, bruxaria e feitiçaria, sistemas de pensamento de que provavelmente faríamos bem em nos livrar no mundo moderno. No entanto, os ataques de nervos e coisas que tais têm uma função simbólica muito fundamental que eu acredito que deveria ser retida. Além do mais, a cultura pós-industrializada convencional faria bem em cultivar mais expressões como essas" 
Foi também em 1988 que se publicou o primeiro texto de translação do reducionismo biomédico para o que chamarei aqui de reducionismo de "gênero". Trata-se do artigo em que Susan Cayleff desenvolve a idéia de que o nervoso contemporâneo nada mais é que a reencarnação de uma antiqüíssima entidade da "teoria médica ocidental", que engloba "útero migratório, possessão demoníaca, tarantismo, melancolia, histeria, simpatia nervosa, nervosismo e neurastenia"72 e que tem, nesse sentido, "simbolizado explicitamente a desvalorização, a 'alteridade' e a vulnerabilidade psicofisiológica da mulher". ${ }^{73}$ A autora parece fortemente impressionada pelo imaginário histórico do sistema da neurastenia, cujas características considera capazes de se sobrepor às do material etnográfico contemporâneo, tanto popular quanto "médico". É, aliás, tomada de Beard (o "criador" da neurastenia) a locução "prisioneiras de sua própria fraqueza", que dá título ao trabalho.

O fato de haver uma relação privilegiada entre nervos e gênero feminino, reconhecido explicitamente por quase toda a literatura, suscita entre diversos autores uma associação linear das características de subordinação ou dominação das populações estudadas e aquelas que distinguiriam de forma homóloga as mulheres, mesmo que essa impressão não se traduza em uma proposta mais abrangente como a de Cayleff. Produz-se assim uma ampla contrapartida "de gênero" à redução "política" do nervoso, que pode ora se opor, ora se somar a esta outra: "Os nervos - no passado e no presente são usados universalmente pelas mulheres para explicar e juntar os acontecimentos da vida. Na medida em que os nervos focalizam os problemas sociais e emocionais da mulher, eles podem ser vistos como uma metáfora do descontentamento". ${ }^{74}$

A mesma associação entre nervos e posição social subordinada ou desprivilegiada expressa-se na interpretação do nervoso como resultado ou expressão de uma marcante e específica experiência de dirupção. Convivem aí a idéia mais geral de "mudança social" ou "modernização",75 e a idéia

(idem, pp. 86-7)

72 S. Cayleff, "Prisoners of their...", op. cit., p. 1199.

73 Ibidem.

74 D. L. Davis, "George Beard and...", op. cit., p. 111, grifos meus.

75 A representação de que as perturbações sofridas têm a ver com dirupções externas violentas é generalizada e importante entre os que utilizam o código do nervoso (cf. M. H. Clark, "Nevra in a Greek...", op. cit., p. 215 ou L. F. Duarte, Da Vida Nervosa (Nas Classes..., op. cit., p. 168). É provavelmente também necessário que se reconheça quie a relação entre dirupção externa e perturbação interna seja, em si, universal. Não poderia ser no entanto atribuída especificamente ao nervoso, já que a maior parte das culturas humanas se utilizou de outros recursos simbó- 
específica de "migração". Este último tema não poderia deixar de estar presente, dada a forte incidência nessa literatura de estudos voltados para grupos de minorias migrantes para o território dos EUA. Na medida, porém, em que não há mais nenhum grupo cultural que não esteja sendo afetado por uma "mudança social" mais ou menos intensa, esse critério de desencadeamento de nervosismo dificilmente explicaria a sua específica e restrita localização. De um modo geral, seria também aplicável aqui a ponderação de que, se a perturbação ou distress é a expressão vivencial da experiência de dirupção das condições de reprodução, não se pode nem supor que essa expressão se dê sempre do mesmo modo, nem que ela tenha de se vazar na linguagem culturalmente específica dos nervos.

A Antropologia Médica norte-americana devota uma justificada atenção à maneira como a representação do nervoso desafia o dualismo fundamental das concepções ocidentais modernas sobre a pessoa. Setha Low já afirmava em 1985: "ele sempre apresenta a propriedade especial de ser um sintoma sem a dicotomia entre mente (mind) e corpo", ${ }^{76}$ inaugurando assim, provavelmente, uma longa série de interpretações que postulam a inexistência dessa dicotomia nas formas etnográficas do fenômeno do nervoso. Como é inevitável em nossa cultura, a categoria inglesa habitual de mind tem uma extensão semântica mais complexa que a de body/corpo (a que correspondem os adjetivos sinônimos físico, somático e orgânico). A maneira como alguns dos trabalhos estudados se referem à mind revela que a ela estão associados os "sentimentos" e as "emoções" e que o seu adjetivo correlato não é "mental" ou "moral", mas "psíquico" ou "psicológico": "Ao rejeitar a dualidade mente/corpo da biomedicina, nervios expressa ao mesmo tempo a dor física e psíquica". ${ }^{77} \mathrm{Na}$ verdade, a força da psicologização impõe. inclusive, que uma das referências à dicotomia seja feita sob a forma clássica do "soma"/"psyche", hoje associada tão caracteristicamente ao modelo psicanalítico. ${ }^{78}$ Minha própria hipótese a respeito privilegiava, ao contrário, o caráter mediador de todo esse conjunto semântico, de fio de relação entre o físico e o moral ${ }^{79}$ - tão radicalmente separados e segregados na tradição cartesiana. Pois, com efeito, os nervos não abolem o dualismo físico-moral,

licos para falar de suas perturbações.

76 S. M. Low, "Culturally Interpreted Symptoms...”, op. cit.. p. 189.

77 P. J. Guarnaccia e P. Farias. "The Social Meaning...”. op. cit.. p. 1229.

78 Ver, por exemplo. S. M. Low. "Gender, Emotion, and...". op. cit., p. 137 ou. na produçẫo européia, G. Lagadec. "Discours des Malades...". op. cit.. p. 16.

79 L. F. Duarte, Da Vida Nervosa (Nas Classes..., op. cit., cap. Vd. 
mas constituem, antes, uma verdadeira teoria das conexões e fluxos possíveis entre as duas dimensões, tal como foram anteriormente no Ocidente o sistema clássico dos humores ou dos temperamentos ${ }^{80}$ e o sistema da degenerescência. ele mesmo já articulado a partir da configuração do nervoso. ${ }^{81}$ Compreende-se assim que - como testemunham todas as etnografias - seja possível, segundo a lógica do nervoso, que um evento físico possa acarretar reações morais ou uma experiência moral ter implicações físicas, sem que, no entanto, se deixe de distinguir entre os dois planos.

Uma implicação muito importante dessa qualidade eminentemente relacional dos nervos é a de compor uma teoria não-psicologizada do humano. Os nervos são pensados como um meio físico de experiências tanto físicas quanto morais - em perfeita oposição à idéia do psiquismo, concebido para substituir o antigo nível moral e estabelecer sobre o físico uma nova hegemonia. Os nervos são uma típica representação relacional da pessoa, enquanto o psiquismo é uma representação individualizada, associável às marcas ideológicas mais amplas da modernidade ocidental. Não é surpreendente, portanto, que a literatura examinada confirme a radical diferença que opõe no interior mesmo dos EUA a representação da pessoa dos segmentos sociais mais afinados com a dimensão moderna da "grande tradição" ocidental (individualizada e psicologizada) e a daqueles outros que, por muitos motivos. continuam a expressar a antiga ordem relacional. ${ }^{82}$ Nesse sentido, é significativo o uso feito pela Antropologia Médica norte-americana da categoria "psicossocial" para tentar cobrir o abismo entre o nível do indivíduo (representado como "psicológico") e o das relações (resumidas, neste caso, na idéia do "social"). Os nervos e tudo o que lhes diz respeito são, porém. inconvenientemente descritos enquanto fenômeno "psicossocial", por expressarem justamente uma visão de mundo não-individualizada e não-psicologizada. Repetir-se-ia aqui o embaraço, antes analisado, do uso de categorias psicopatológicas para compreender as perturbações nervosas. ${ }^{83}$

80 Cf. J. Pigeaud, La Maladie de l'Ame: Étude sur la Relation de l'Ame et du Corps dans la Tradition Médico-Philosophique Antique, Paris, S. E. Belles Lettres, 1981, p. 125.

81 Cf. L. F. Duarte, "A Psychopathia Sexualis de Krafft-Ebing, ou o Progresso Moral pela Ciência das Perversōes", Cadernos do IMS, vol. 2. n 3, agosto/setembro de 1988.

82 Cf. M. Kay e C. Portillo, "Nervios and Dysphoria...", op. cit., pp. 281 e 287: J. Jenkins. "Conceptions of Schizophrenia...", op. cit., pp. 1237 e 1240; P. J. Guarnaccia et alli, "Si Dios Quiere...", op. cit., p. 194.

83 A dificuldade de relativizar a representaçāo psicologizada moderna pode se expressar na idéia de que o nervoso é exclusivamente "físico", já que não é "psicológico". como em E. A. Barnett. "Notes on Nervios...", op. cit., p. 164. Pode também se manifestar na crítica a esta posição e 
Outra característica central da configuração nervosa bem percebida pela literatura é o fato de permitir conceber continuidade entre as múltiplas perturbações mais leves ou fracas e aquelas mais graves que se aproximam da "loucura" (por mais variável que possa ser a representação deste pólo) ${ }^{84}$ Trata-se de mais uma implicação da relacionalidade básica dessa visão de mundo, descomprometida com a definição substantivada ou reificada de "doenças mentais" (com seus corolários de imanência e permanência). ${ }^{85}$

O caráter relacional do nervoso manifesta-se tanto na possibilidade de transitar entre as pequenas perturbações quotidianas e a loucura, quanto na de fazer depender a classificação de cada caso, a avaliação de sua realidade ou gravidade, da situação social em que se entrelaçam a pessoa observada e seu classificador. Essa outra característica, inseparável da "continuidade", foi por mim classificada sob a rubrica das "propriedades de situação" ${ }^{86}$ É assim que um mesmo conjunto aparente de comportamentos ou sentimentos de perturbação pode ser incluído em diferentes séries semânticas por meio do fio mediador dos nervos, expressando as atitudes positivas ou negativas implicadas na "situação" em jogo. As freqüentes possibilidades de combinação ou transição entre interpretações de cunho religioso (no pólo mais moral do físico-moral) e de cunho médico-psiquiátrico (no pólo mais físico do físico-moral) ganham seu pleno sentido apenas contra o pano de fundo dessa língua franca do nervoso.

Uma generalizada tendência individualista e pragmatista faz acompanhar a percepção do caráter situacional das classificações nervosas de interpretações de "manipulação" ou "negociação" das regras e códigos. O que

na defesa de que a representação nervosa já é "psicológica", por não ser exclusivamente "física", tal como propôs na produção brasileira J. F. Costa, "A Consciência da Doença enquanto Consciência do Sintoma: A 'Doença dos Nervos' e a Identidade Psicológica', Cadernos do IMS, vol. 1, n ${ }^{\circ} 1,1987$, pp. 9-10.

84 L. F. Duarte, Da Vida Nervosa (Nas Classes..., op. cit., pp. 259 e ss.

85 Embora a percepção dessa continuidade seja explícita em diversos autores analisados, é notável a dificuldade de produzir a referência analítica sem o recurso às representações psicologizadas (quando não diretamente psiquiátricas). Ver o exemplo seguinte, em que o uso da categoria "doença mental" para designar o continuum das perturbações viola justamente essa relacionalidade que os autores estâo querendo expressar: "As concepções de doença mental de muitas famílias hispânicas enraizam-se em modelos culturais que encaram a doença mental como um continuum. Essas idéias sobre a doença [illness] permitem às famílias acolher os seus próprios membros e manter esperanças quanto ao futuro" (P. J. Guarnaccia et alli, "Si Dios Quiere...", op. cit., p. 211). Ver, também, S. M. Low, "The Meaning of...", op. cit., p. 38: Dinham apud S. M. Low, "Culturally Interpreted Symptoms...", op. cit., p. 194; J. Jenkins, "Conceptions of Schizophrenia...", op. cit., p. 1239.

86 L. F. Duarte, Da Vida Nervosa (Nas Classes..., op. cit., p. 195. 
Dona Davis também chamou corretamente de "regras situacionais" (situational rules $)^{87}$ é reduzido em outro autor a "um mecanismo de defesa adaptativo", existente para permitir que "o indivíduo possa então optar por se engajar na mudança e no controle das questões que podem ser mudadas". ${ }^{88}$ A dimensão de manipulação quotidiana dos códigos sociais é real e universal (e reconhecida pelos próprios informantes no caso do nervoso); ela é, porém, uma propriedade do sistema e não a sua explicação, a sua razão de existência social.

As propriedades de situação permitem que o código do nervoso seja efetivamente dotado de uma flexibilidade ímpar ${ }^{89}$ que pode facultar — dado o continuum das perturbações - a recusa ou o abrandamento do efeito estigmatizante do comportamento desviante ${ }^{90}$ e permitir, portanto, que se possa associar a prevalência do código do nervoso a estados de maior capacidade de integração social. ${ }^{91}$ Uma das possibilidades intrínsecas do sistema é a de comportar avaliações de "simulação" pelos próprios informantes, tal como referido por Clark ${ }^{92}$ para a Grécia rural. ${ }^{93} \mathrm{O}$ necessário reconhecimen-

87 D. L. Davis, "The Variable Character of...", op. cit., pp. 73-4.

88 C. S. Wolf-Dresp, "Nervios as a Culture-Bound...", op. cit., p. 134.

89 N. Scheper-Hughes, "The Madness of Hunger...", op. cit., p. 442 ou 445, para um exemplo etnográfico.

90 R. Finerman, "The Burden of...", op. cit., p. 152.

91 Ver, por exemplo: "A classificação do sofrimento de meus informantes como nervios tem uma importante função normalizadora e integradora. Em primeiro lugar, como os nervios são uma condição que pode afetar qualquer pessoa que esteja sofrendo um alto grau de stress, nenhuma distinção qualitativa nítida será feita entre o paciente e o resto da comunidade. Ao definir seu sofrimento como nervios, os informantes não se definiram a si próprios como pacientes psiquiátricos" (M. Swerdlow, “'Chronicity', 'Nervios', and...", op. cit., p. 221). Ou ainda: "O fato de identificar um problema de uma forma menos estigmatizante, como 'nervoso' e não como alguma forma de 'doença mental', por exemplo, pode permitir diferenciadamente que haja incorporação continuada da pessoa doente nos grupos sociais" (J. Jenkins, "Conceptions of Schizophrenia...", op. cit., p. 1234). Essa característica do nervoso também atraiu a atenção dos que trabalham com saúde mental no Brasil, no contexto da luta antimanicomial. Os trabalhos de Vertzman e de Vasconcelos são um bom exemplo de expressão dessa atenção a um modo de representação popular que permitiria visualizar outras formas mais integradas de trato com a "doença mental" (J. S. Vertzman, Pensando nos Problemas da Vida. Os Discursos sobre Tristeza e Depressão numa População Favelada Atendida em Posto de Saúde no Rio de Janeiro, Tese de Mestrado, Instituto de Psiquiatria/UFRJ, 1992; E. M. Vasconcelos, The New Alienists of the Poor: Developing Community Mental Health Services in Brazil - 1978/1989, Ph.D. Thesis, London School of Economics and Political Science/University of London, 1992, p. 305: E. M. Vasconcelos, Do Hospicio à Comunidade, Belo Horizonte, SEGRAC, 1992).

92 M. H. Clark, "Nevra in a Greek...", op. cit., p. 206.

93 Essa "simulação", com toda as ambigüidades que comporta nas situações concretas, esteve na 
to do nervoso enquanto "instrumento de negociação de status"94 ou enquanto "'gestão da imagem social" (impression management) ${ }^{95}$ às vezes, infelizmente, ocorre de modo a reforçar as leituras reducionistas da dominação de classe ou de gênero, como essa espécie de "consciência prática" a que me referi anteriormente.

A demonstração do peso e importância das instâncias da família e da localidade é uma das contribuições marcantes da etnografia do nervoso na Antropologia Médica norte-americana. Setha Low já se referia à "dirupção familiar" e a "relações familiares difíceis" como primordiais no desencadeamento das perturbações nervosas. ${ }^{96}$ Desde então a dimensão das relações familiares não deixou de ser mencionada nas mais diversas situações etnográficas, ainda que apenas justaposta às demais instâncias causais ou "etiológicas". ${ }^{97}$ Corroborando meus prớprios dados e interpretação, ${ }^{98}$ alguns autores procuraram, porém, conceder a essa evidência etnográfica um estatuto analítico mais sistemático. A categoria de "sociocentrismo", aplicada às culturas onde viceja o código do nervoso por Guarnaccia \& Farias e por Swerdlow, ${ }^{99}$ não deixa de ser expressiva do caráter de relacionalidade básica com que se pode qualificar os grupos sociais menos expostos à individualização moderna e portadores desse tipo de representação. Van Schaik expressa a mesma idéia ao afirmar que o nervoso é "uma expressão das relações

raiz de meu interesse pelo assunto, dado o seu peso nas interavaliações locais relativas ao "encosto no INPS" (obtenção de licenças médicas ou aposentadorias precoces por meio do sistema nacional de saúde e previdência) (Cf. L. F. Duarte. "Doença dos Nervos...", op. cit.: L. F. Duarte. Da Vida Nervosa. Pessoa e.... op. cit.; L. F. Duarte, What it Means.... op. cit.). Outro dos primeiros textos brasileiros de Ciências Sociais a se ocupar diretamente do nervoso também se incluia na perspectiva manipuladora, mencionando - enquanto "estratégias" - os complexos comportamentos do "encosto" (M. C. G. Souza, "'Doença dos Nervos", uma Estratégia de Sobrevivência", A Saúde no Brasil, vol. 1, n 3, 1983, pp. 131-9).

94 Cf. D. L. Davis, "George Beard and...", op. cit., p. 111.

95 D. L. Davis, "The Variable Character of...", op. cit., p. 75.

96 Ou, de forma ainda mais explícita: "Nos dados sobre a Costa Rica, há provas consideráveis de que. tanto de um ponto de vista analítico quanto do ponto de vista do informante. os problemas familiares freqüentemente acarretam sofrimento [distress] fĭsico e mental, muitas vezes expresso sob a forma sintomática dos nervios" (S. M. Low. "The Meaning of...". op. cit. . pp. 34-5).

97 Ver a revisão parcial disponível em D. L. Davis e P. J. Guarnaccia, "Health. Culture and....", op. cit.. p. 4.

98 L. F. Duarte, Da Vida Nervosa (Nas Classes..., op. cit.. pp. 212 e ss.

99 "O nervoso representa uma doença [sickness] elaborada na sociocêntrica cultura latina. na qual as identidades das pessoas são formadas por suas conexões com a família, com a comunidade e com o pais" (P. J. Guarnaccia e P. Farias, "The Social Meaning...”. op. cit.. p. 1229). Ver, ainda, M. Swerdlow. '“'Chronicity'. 'Nervios', and...", op. cit., p. 26. 
sociais". ${ }^{100}$ Compreende-se que não haja, assim, uma mera conjunção etnográfica entre os dois temas: as pessoas que expressam suas perturbações físico-morais por meio do código do nervoso têm sua identidade construída dentro da rede relacional familiar (mais do que por uma "individualidade"). Superpõem-se assim (ou se solidarizam) os níveis conceitual (cultural, ideológico, simbólico) e sociológico (relações ou organização social), desafiando os preconceitos da ideologia moderna.

Aqui, os dados etnográficos também são concordes em enfatizar a preeminência das identidades sociais construídas tendo como base as redes locais ou vicinais (o que Swerdlow chama de "organização social de nível local"), ${ }^{101}$ nos múltiplos contextos em que prevalece a lógica do nervoso. Trata-se do caráter "relacional básico" a prevalecer ainda uma vez sobre as demarcações sociais "adquiridas", que caracterizam os grupos sociais individualizados. ${ }^{102}$

De modo geral, pode-se dizer que é só contra o pano de fundo dessa compreensão da importância da família e da localidade, enquanto manifestações de uma relacionalidade estruturante, que se pode entender essa outra marcante e reiterada característica do nervoso, que é a sua associação primordial com o gênero feminino. Por oposição à leitura denunciadora da dominação de gênero, pode-se dizer aqui - como propus em meus trabalhos anteriores - que a mulher é mais nervosa por ser mais relacional. Com efeito, em todas as situações etnográficas envolvidas, a mulher representa o lado interior, englobado, da família e da localidade, por oposição ao princípio masculino, associado à exterioridade, ao mundo público do trabalho e da representação política. Essa configuração é solidária com a representação da construção físico-moral diferencial da mulher, articulada em uma associação muito peculiar entre cabeça e corpo, sangue e nervos, força moral e fraqueza física, que se opõe simétrica e complementarmente à representação do masculino. ${ }^{103}$

100 E. Van Schaik, “Paradigms Underlying...", op. cit., p. 26.

101 M. Swerdlow, “'Chronicity', 'Nervios', and...”, op. cit., p. 217.

102 Há inclusive o curioso caso etnográfico de Grey Rock Harbour em que o nervoso parecia servir de expressão à forte singularidade da identidade local: "o nervoso é [...] uma poderosa metáfora, que serve como um princípio de organização dos símbolos na cultura comportamental e expressiva de Grey Rock Harbour" (D. L. Davis e R. Whitten, "Medical and Popular...", op. cit., p. 1218). Há notáveis homologias, nesse sentido, entre esse porto pesqueiro da Terra Nova canadense e o bairro pesqueiro de Jurujuba (RJ), que serviu como foco etnográfico primeiro de meus trabalhos sobre esse assunto (L. F. Duarte, Da Vida Nervosa (Nas Classes..., op. cit.).

103 A especificidade da construção do feminino nas culturas populares ocidentais é reduzida na 
Esta revisão da literatura médico-antropológica norte-americana sobre o nervoso só se justifica na medida em que possa contribuir para demonstrar que esse fenômeno é privilegiado para compreender as questões centrais da definição da cultura ocidental moderna e seus limites e descontinuidades. A noção de pessoa específica da configuração ideológica a que se tem chamado de "individualismo" atravessa todo o horizonte cosmológico em que se tem movido essa cultura (e todos os saberes que lhe são associados, como a Medicina ou a Antropologia). Os nervos dificilmente poderiam ser compreendidos a partir de uma estratégia puramente empirista, que fosse apenas superpondo dados etnográficos locais descomprométidos com uma teoria mais ampla a respeito da mudança e da diferenciação cultural dentro das sociedades afetadas pela modernização individualista.

Como referi anteriormente, parece haver uma certa correlação entre a utilização plena do código do nervoso e um modo cultural associado à relacionalidade, à complementaridade e à hierarquia. $\mathrm{O}$ modo que se lhe opõe - mutualista, singularizante e individualizante - se expressa de modo privilegiado mediante as representações psicologizadas da pessoa, seja sob as formas biomedicalizantes da psiquiatria (associadas, nesse caso, a uma ênfase mais linear na ideologia da vontade individual), seja sob as formas simbolizantes da psicanálise (mediadas pela representação de um inconsciente individual). ${ }^{104}$ Essa proposta analítica é antropológica por excelência na medida em que se pretende comparativa e relativista. Sua formulação depende de um radical estranhamento em relação aos valores centrais da versão

literatura estudada a pouco mais do que a questão da menopausa, como em D. L. Davis, Blood and Nerves: An Ethnographic Focus on Menopause, s/l, St. John's Memorial University of Newfoundland, 1983 e E. A. Barnett, "Notes on Nervios...", op. cit. (que inclui também o sistema classificatório do quente/frio). A riqueza semântica do par de oposição força/fraqueza (cf. L. F. Duarte, Da Vida Nervosa (Nas Classes..., op. cit., pp. 145 e ss.) é tematizada por Nancy Scheper-Hughes apenas no que reforça sua leitura de "dominação" nas relações entre "ricos" e "pobres" (cf. N. Scheper-Hughes, "The Madness of Hunger...", op. cit., p. 444 e N. Scheper-Hughes, Death without Weeping..., op. cit., p. 188).

104 Os fundamentos teóricos dessa proposta se encontram, sobretudo, na teoria da hierarquia e na análise do individualismo de Louis Dumont (L. Dumont, Homo Hierarchicus, Londres, Palladin, 1972; L. Dumont, Homo Áqualis: Génèse et Ëpanouissement de l'Idéologie Économique, Paris, Gallimard, 1977; L. Dumont, O Individualismo. Uma Perspectiva Antropológica da Ideologia Moderna, Rio de Janeiro, Rocco, 1985), mas abarcam sugestões fundamentais de Durkheim, Simmel, Tönnies, Weber e Foucault. As referências sobre a crescente literatura contemporânea a esse respeito, inclusive brasileira, se encontram em meus trabalhos já citados. Convém realçar no contexto dessa discussão que a dicotomia "hierarquia"/"individualismo" não é uma reprodução da dicotomia "tradicional"/"moderno", no sentido de que não endossa a dimensão evolutiva necessária desta última. 
"moderna" de nossa cultura, retendo de certa forma apenas a disposição universalista (que, embora também culturalmente específica, é a garantia da manutenção da empresa antropológica). Ela exige, porém, redobrados cuidados no trato com os dados. A complexidade das sociedades ocidentais modernas arma-se sobre uma multiplicidade de eixos, ora permitindo aparente convivência de planos simbólicos muito distintos, ora sugerindo a dissociação entre outros tantos essencialmente homólogos. A dicotomia entre hierarquia (ou holismo, nos termos de Dumont) e individualismo pode fazer sentido entre teorias eruditas ou populares da pessoa (como são o nervoso e o psicologismo), mas pode também fazer sentido entre culturas nacionais, entre culturas de classe, entre experiências de gênero ou entre diferentes momentos da história da cultura ocidental. É do difícil cruzamento de muitas dessa linhas de interpretação que se pode obter eventualmente algum efeito heurístico que escape ao senso comum.

A leitura médico-antropológica do nervoso traz à discussão todo um tesouro de informação etnográfica. As grandes teorias que se propõem organizá-la foram aqui resenhadas: uma teoria biomédica que vê nesses fenômenos a mera expressão da doença orgânica (mesmo que sob sua forma psiquiátrica), e que é o horizonte de crítica da maior parte dos autores examinados; uma teoria psicologizante que os vê como expressão do funcionamento das emoções e do psiquismo individual e que permanece apenas em estado virtual, por não poder desprezar a dimensão social de seus objetos (donde a necessidade da locução "psicossocial"); uma teoria sociológica que os encara como expressão ou reflexo da realidade última do conflito de classe ou de gênero e da dominação daí decorrente (assim como das perversas condições de reprodução social que lhe poderiam ser atribuídas), e que não dispõe de recursos para lidar com a especificidade desse código (por oposição a tantos outros que falam de sofrimento e perturbação em situações de diferença social). ${ }^{105}$

Nenhuma dessas teorias, porém, trata da diferenciação cultural em si. Esta se impõe por meio dos dados etnográficos, que nos aportam ao mesmo tempo uma surpreendente extensão da pertinência do código do nervoso

105 Philippe Corcuff analisa, por exemplo, como os ferroviários franceses se vêem obrigados a verter seus "problemas nervosos" para a linguagem psicologizada do sistema de perícias psicotécnicas da empresa e a lidar com essaa lógica a ponto de montar em seu sindicato um contrasistema psicológico e psiquiátrico (P. Corcuff, "Sécurité et Expertise Psychologique dans les Chemins de Fer”, in L. Boltanski e L. Thévenot, eds., Justesse et Justice dans le Travail, Paris, PUF, 1989). 
(entre grupos, países e continentes) e uma não menos surpreendente e concomitante descontinuidade no seu uso ou legitimidade (dentro de grupos, países ou continentes). O que faz, afinal, com que haja algo em comum entre migrantes porto-riquenhos e gregos nos EUA, trabalhadores urbanos baladi no Cairo, pobres habitantes do Kentucky ou de uma aldeia da Terra Nova, as elites européias do século XIX e as elites contemporâneas do sul dos EUA (segundo a estimulante e episódica informação de Davis \& Guarnaccia)? ${ }^{106}$

A percepção de que o código do nervoso é solidário com uma verdadeira e integrada representação da pessoa e que esta, por sua vez, só pode existir dentro de uma configuração cultural específica, tem de passar, em primeiro lugar, pela superação da confusão entre sua condição de código cultural e o eventual reconhecimento da existência de nervos no corpo humano. Se esse código não pode prescindir da antecedência histórica e lógica do saber fisiológico sobre o sistema nervoso desencadeado entre os séculos XV.II e XVIII, ${ }^{107}$ ele quase nada mais lhe deve em suas formas contemporâneas. Procedimento homólogo seria necessário para evitar a confusão entre a representação do "psicológico" e o reconhecimento da existência de emoções e sentimentos que se desencadeiam no plano pessoal (se não necessariamente "individual") e sobre os quais se puderam ancorar, neste último século, inúmeras teorias.

Trata-se, em seguida, de admitir que existe realmente uma "cultura ocidental" e que ela tem a sua história marcada pelo desenvolvimento e crescente hegemonização da ideologia ou configuração ideológica do "individualismo" (apesar de abarcar uma miríade de segmentações culturais em outros níveis, recortadas segundo diferentes eixos). Essa hipótese permite observar sob nova luz a evolução das teorias sobre a pessoa desde a Antiguidade Clássica e, particularmente, as representações sobre os nervos, tão facilmente reduzidas a um fio linear de progresso nas referências citadas. Os saberes antigos dos nervos nunca constituíram a base de uma teoria da pessoa. ${ }^{108}$ Eles contribuíram para as especulações correntes sobre a consti-

106 D. L. Davis e P.J. Guarnaccia, "Health, Culture and...", op. cit., p. 11.

$107 \mathrm{O}$ fato de o léxico contemporâneo do nervoso derivar seguramente dos saberes fisiológicos eruditos setecentistas, confere plena ininteligibilidade à afirmação de $\mathrm{M}$. Lock de que "nerves/nevra/nervios dificilmente podem ser consideradas palavras novas, e certamente não palavras de que os povos oprimidos tenham se reapropriado daqueles que detêm o poder" (M. Lock, "Words of Fear...", op. cit., p. 86).

108 Cf. F. Solmsen, "Greek Philosophy and the Discovery of the Nerves", Museum Helveticum, vol. 18, nº 4, 1961; J. Pigeaud, La Maladie de ..., op. cit.; P. Lain-Entralgo, Historia Universal de la Medicina, Barcelona, Salvat, 1972. 
tuição humana, tais como as teorias sobre a relação entre o coração e o cérebro (e os pneuma), mas mantiveram-se subordinados às teorias da alma e à configuração dos humores e temperamentos até o século XVIII.

É só então, no bojo das grandes transformaçães culturais e sociais que dão nascimento à versão dita "moderna" da cultura ocidental, que os nervos são reapropriados em um sistema mecanicista integrado (justamente o "sistema nervoso"), servindo de suporte para um novo sujeito representado como imanente, autônomo e universalmente idêntico, capaz de suportar os nascentes ideais da "liberdade" e da "igualdade". ${ }^{109}$ Sabe-se, porém, qual foi o destino dessa representação ao longo de todo o século XIX: servir à paulatina reconstituição de uma configuração de diferenças, relacional, hierárquica, que culminou nos modelos da degenerescência e da neurastenia. São estas formas, derivadas do saber fisiológico setecentista e reconvertidas a uma lógica hierárquica, que os movimentos médico-higienistas repassam a todas as populações afetadas pela cultura ocidental. Ao final do século XIX, a força das idéias individualizantes impõe o surgimento de uma nova configuração da pessoa, a dos saberes psicologizados (sobretudo a partir da influência da Psicanálise e em oposição ao saber considerado antiquado dos nervos). As classes populares, em geral no Ocidente, e eventualmente os segmentos periféricos ou "atrasados" das elites, continuaram, porém - e continuam até hoje - , a dispor de um modelo de pessoa condizente ou solidário com suas próprias resistências à individualização (no sentido de conversão à ideologia "culta" do individualismo).

109 Cf. M. Foucault, História da Loucura na Idade Clássica, São Paulo, Perspectiva, 1978, caps. 8 e 9; M. Gauchet e G. Swain, La Pratique de l'Esprit Humain (l'Institution Asilaire et la Révolution Démocratique), Paris, Gallimard, 1980; L. F. Duarte, Da Vida Nervosa (Nas Classes..., op. cit., cap. IIIb. Sobre diversos aspectos dessa interpretação é preciso agregar os importantes textos de E. Carlson e M. Simpson, "Models of the Nervous System in Eighteenth Century Psychiatry", Bulletin of the History of Medicine, vol. 63, $\mathrm{n}^{\circ} 2,1969, \mathrm{pp} .101-15 ; \mathrm{K}$. M. Figlio, "Theories of Perception and the Physiology of Mind in the Late Eighteenth Century", History of Science, $\mathrm{n}^{\circ}$ 13, 1975, pp. 177-212; C. J. Lawrence, "The Nervous System and Society in the Scottish Enlightenment", in B. Barnes e S. Shapin, eds., Natural Order, Londres, Sage Publications, 1979, a que só tive acesso mais recentemente e que corroboram plenamente a correção de minha proposta. Como diz Figlio, por exemplo: "a inteireza do sentido do eu [wholeness of the sense of self] implicava a unidade do órgão dos fenômenos mentais" (K. M. Figlio, "Theories of Perception...", op. cit., p. 179). Ou ainda Lawrence: "Na teoria fisiológica, a medicina escocesa [do século XVIII] se caracterizava pela ênfase na integração total das funçōes corporais, pela capacidade perceptiva ou sensibilidade do organismo e pela preocupação com o sistema nervoso enquanto base estrutural dessas propriedades" (C. J. Lawrence, "The Nervous System...", op. cit., p. 19). 
Portanto, não é por participarem, por exemplo, de uma cultura "latina" (ou hispano-americana) que os Mexican-Americans ou os migrantes porto-riquenhos ou salvadorenhos nos EUA representam suas perturbações físicomorais por meio do código do nervoso. Não é, tampouco, por fazerem parte de uma cultura circumediterrânea que os aldeões gregos ou os trabalhadores cairotas também pensam sofrer por causa de seus nervos. ${ }^{110} \mathrm{Nem}$ é, ainda — como bem criticou Van Schaik ${ }^{111}$ —, por partilharem de uma "cultura da pobreza" que os mineiros dos Apalaches falam dos nervos ao expressar seu distress. Eles têm em comum com muitos outros grupos sociais contemporâneos ou oitocentistas sua não-individualização pela psicologização, por oposição aos Anglo Americans da análise de Jenkins, ${ }^{112}$ às viúvas Mexican American mais aculturadas da análise de Kay \& Portillo, ${ }^{113}$ à institutrice psicanalizada paciente de Lagadec ${ }^{114}$ ou aos membros em geral das classes letradas de Boston, de San Jose da Costa Rica, do Rio de Janeiro ${ }^{115}$ ou de Atenas.

A apropriação do fenômeno do nervoso por essa via analítica também permite compreender que os explorados e famintos habitantes do Nordeste brasileiro descritos por Scheper-Hughes ${ }^{116}$ possam expressar sua perturbação em um código que serviu à manifestação de outras perturbações entre os personagens de Jane Austen ${ }^{117}$ ou os de Marcel Proust. ${ }^{118}$ A própria oposição entre cultura laica $x$ cultura profissional, tematizada por vários autores, ganha novos contornos desde que se compreenda que o nervoso não é $a$ cultura laica, mas uma das culturas laicas possíveis (como há hoje uma

110 Cf. M. H. Clark, “Nevra in a Greek...", op. cit.; L. Krieger, "Nerves and Psychosomatic...", op. cit.

111 E. Van Schaik, "Paradigms Underlying...”, op. cit.

112 J. Jenkins, "Conceptions of Schizophrenia...", op. cit.

113 M. Kay e C. Portillo, "Nervios and Dysphoria...", op. cit.

114 G. Lagadec, "Discours des Malades...", op. cit.

115 Há, hoje, toda uma literatura histórica e etnográfica sobre o modo de funcionamento das representações psicologizadas da Pessoa no Brasil, cujas referências bibliográficas podem ser encontradas em L. F. Duarte, "Freud e a Imaginação Sociológica Moderna", in J. Birman, ed., Freud - 50 Anos Depois, Rio de Janeiro, Relume-Dumará, 1989 e L. F. Duarte, What it Means..., op. cit.

116 N. Scheper-Hughes, “The Madness of Hunger...”, op. cit. e N. Scheper-Hughes, Death without Weeping..., op. cit.

117 Cf. D. L. Davis e R. Whitten, “Medical and Popular...”, op. cit.

118 Cf. L. F. Duarte, "A Representação do Nervoso na Cultura Literária e Sociológica do Século XIX e Começo do Século XX", Anuário Antropológico 87, Rio de Janeiro, Ed. UnB/Tempo Brasileiro, 1990, pp. 93-116. 
psicologizada e houve certamente outrora uma outra humoral) que se enfrentam com uma cultura profissional quase completamente afastada do modelo nervoso ${ }^{119}$ e comprometida com alguma das versões do saber psicologizado contemporâneo sobre a Pessoa. A compreensão dos embaraços (e perturbações) decorrentes desse descompasso entre teorias da perturbação no confronto entre terapeuta e paciente (mas também, em alguns casos, entre agentes religiosos e fiéis demandando respostas à aflição) é, sem dúvida, uma das frentes de pesquisa mais urgentes e sérias. Alguns dos trabalhos resenhados apresentam referências etnográficas interessantes a esse respeito, sem que possam efetivamente ultrapassar o nível da mera constatação ou registro da descontinuidade cultural. ${ }^{120}$ Essa perspectiva analítica não desqualifica a importância do conhecimento sobre as condições sociais e culturais associáveis à expropriação e fome dos trabalhadores do Nordeste brasileiro, à desvairada violência que cerca os moradores pobres de Belfast ${ }^{121}$ ou às eventuais perversões dos modelos hierárquicos de relação entre os gêneros, etnias ou classes. Pondera apenas que o modelo do nervoso é algo mais abrangente e mais complexo que a sua utilização nesses contextos dramáticos e que maiores vantagens críticas decorreriam da dissociação metodológica desses objetos de conhecimento que a sua agregação descontrolada. A literatura médico-antropológica resenhada, ao recusar com justiça o determinismo biomédico, opera com a hipótese de uma correlação entre "condições de vida" (ou sociais, ou sócio-econômicas), "perturbações" (distress, sofrimento, aflição etc.) e "nervoso". Reitero, nesse sentido, a necessidade de se distinguir analiticamente os dois níveis de interseção entre as três dimensões: em um primeiro plano, apresentam-se à pesquisa as relações entre as "condições de vida" e o eventual desencadeamento de "perturbações"; em um segundo, as relações entre a existência de perturbações e a eventual utilização do código do "nervoso". Desse segundo nível as "condições de

119 à exceção, possivelmente, de situaçōes nacionais muito específicas, como a da China (cf. A. Kleinman, "Neurasthenia and Depression...", op. cit. e A. Kleinman, Social Origins of..., op. cit.); de saberes francamente marginalizados, como as caracterologias da Antropologia Física; ou das literaturas de "divulgação científica" e "auto-ajuda" (mencionadas, no tocante ao nervoso, em D. L. Davis, "George Beard and...", op. cit.; e em L. F. Duarte, Da Vida Nervosa (Nas Classes..., op. cit.).

120 S. M. Low, "The Meaning of...", op. cit., pp. 36 e 39; C. S. Wolf-Dresp, "Nervios as a Culture-Bound...", op. cit., p. 132; P. Dunk, "Greek Women and...", op. cit., p. 41; P. J. Guarnaccia, V. De la Cancella e E. Carrillo, "The Multiple Meanings...", op. cit., p. 59; J. D. Koss-Chioino, "Experience of Nervousness...", op. cit., p. 261; L. A. Camino, "Nerves, Worriation...", op. cit., p. 306.

121 J. A. Sluka, "Living on their...", op. cit. 
vida" não estarão ausentes, mas estarão aí mediadas ou traduzidas pelo código cultural mais amplo que - ao lhes atribuir um sentido diferenciado, ainda que negativo - fez de sua vida bruta fatos humanos.

\section{RESUMO}

\section{Os Nervos e a Antropologia Médica Norte-Americana:} Uma Revisão Crítica

Trata-se de um levantamento, revisão e análise da ampla literatura norte-americana articulada em torno do campo da Antropologia Médica que se tem dedicado à questão dos nervos, do nervoso ou do ataque de nervos nas últimas décadas. Procura-se apresentar o quadro dos pressupostos analíticos que ordenam as classificações prevalecentes nesse campo, esclarecendo assim não apenas a etnografia comparada do fenômeno dos nervos, mas também a própria estruturação conceitual da Antropologia Médica. Enfatiza-se os riscos dos reducionismos pela dominação/poder e pela dominação/gênero na necessária argumentação crítica contra os paradigmas biomédicos e sua leitura da "doença dos nervos". Argumenta-se por um conhecimento mais acurado da história desse fenômeno e pela sua contextualização no quadro dos demais modelos de pessoa e perturbação físico-moral correntes na cultura ocidental moderna. Procede-se à recuperação dos pontos centrais de contribuição da etnografia produzidos nesse campo para o conhecimento comparado dos nervos, aproximando-o das literaturas brasileira e européia a esse respeito.

\section{ABSTRACT}

\section{The Nerves in North-American Medical Anthropology:}

\section{A Critical Review}

This is a review of the vast and recent North-American bibliography concerning nerves and attacks of nerves from the point of view of Medical Anthropology. The author describes the analytical instruments underlying both the specific ethnographic contribution and the general conceptual frame of Medical Anthropology. He argues against the reductionist use of "power" and "gender" in the otherwise necessary critique of biomedical models of "nervous disease" or "illness". He emphasizes the need of a greater attention to the historical dimension of these phenomena and to their embedded- 
ness in the context of modern Western culture models of the Person and physical-moral perturbations. He accounts for the main ethnographic contributions of that literature for the knowledge of nerves, in a comparison with Brazilian and European sources.

\section{RÉSUMÉ}

Les Nerfs et l'Anthropologie Médicale Nord-Américaine: Une Révision Critique

Il s'agit d'une révision et analyse de la littérature nord-américaine récente sur les nerfs, la nervosité ou les crises nerveuses, axée autour de l'Anthropologie Médicale. L'auteur présente les préssuposés analytiques sousjacents aux classifications courantes dans ce champ, pour mieux saisir à la fois les qualités de l'ethnographie du phénomène des nerfs et la structure conceptuelle de l'Anthropologie Médicale. Il souligne les risques de la substitution de la réduction opérée par le schéma biomédical (justement critiquée en ce qui concerne sa conception de "maladies nerveuses") par ceux du "pouvoir" et des différences de "genre". Il propose une plus forte attention à l'histoire de ce phénomène ainsi qu'à sa position dans le cadre plus vaste des modèles de la personne et des troubles physico-moraux dans la culture occidentale moderne. Il fait le bilan des contributions ethnographiques de cette littérature pour la connaissance comparée des nerfs, en paralèle avec les thèmes présents dans les travaux brésiliens et européens. 
